\title{
Türkiye'de Çiğ Süt ile Perakende Süt Fiyatları Arasındaki Asimetrik İlişki
}

\author{
Merve AYYILDIZ1 ${ }^{\&}$, Adnan ÇIÇEK ${ }^{2}$, Kaan KAPLAN ${ }^{3}$ \\ ${ }^{1}$ Yozgat Bozok Üniversitesi, Ziraat Fakültesi, Tarım Ekonomisi Bölümü, Yozgat, 2,3Tokat Gaziosmanpaşa Üniversitesi, Ziraat Fakültesi, Tarım \\ Ekonomisi Bölümü, Tokat \\ ${ }^{1}$ https://orcid.org/0000-0002-9012-0756, ${ }^{2}$ https://orcid.org/0000-0002-2671-1439, ${ }^{3}$ https://orcid.org/0000-0002-5579-5707 \\ $\triangle$ : merve.ayyildiz@yobu.edu.tr
}

\begin{abstract}
ÖZET
Üretici ve tüketici süt fiyatlarının oluşumunda arz zincirindeki rekabet koşulları büyük ölçüde etkili olmaktadır. Söz konusu fiyatlar arasındaki asimetrik ilişkinin belirlenmesi sektördeki aksaklıkları ve pazar gücünün varlığını belirlemede oldukça önemlidir. $\mathrm{Bu}$ çalışmada, 2005 Ocak - 2019 Aralık dönemine ait çiğ süt ve perakende süt fiyatları kullanılarak asimetrik ilişkinin ortaya konulması amaçlanmıştır. Asimetrik fiyat ilişkisini belirlemede Von CramonTaubadel ve Loy tarafindan geliştirilen asimetrik hata düzeltme modelinden (AECM) yararlanılmıştır. Araştırma sonucunda uzun dönemde perakende süt fiyatlarının çiğ süt fiyatlarındaki azalışlara, artışlara göre daha hızlı tepki verdiği belirlenmiştir. Bu sonuç, süt sanayisinin daha rekabetçi bir yapı kazandığına önemli bir işaret olarak kabul edilebilir. Diğer yandan fiyat oluşumlarında ve fiyat istikrarında iyileşmeler gözlenirken kalite standardı ile haksız rekabet koşullarının varlığı göz ardı edilemez. Bu bağlamda, süt sanayiinde gıda kodeksine uygun şartlarda kaliteli üretimi de teşvik eden politikalar geliştirilmeli ve buna yönelik denetim sistemi güçlendirilmelidir.
\end{abstract}

\section{Asymmetrical Relationship Between Raw Milk and Retail Milk in Turkey}

\begin{abstract}
Competitive conditions in the supply chain are influential on the formation of producer and consumer milk prices. Determining the asymmetrical relationship between the mentioned prices is very important in terms the disruptions in the sector and the presence of market power. In this study, it is aimed to reveal the asymmetric relationship by using raw milk and retail milk prices for the period 2005 January - December 2019.. Asymmetric error correction model (AECM) developed by Von Cramon-Taubadel and Loy was used to determine the asymmetric price relationship. As a result of the research, it was determined that retail milk prices react more rapidly to decreases in raw milk prices in the long run. This result can be considered as an important sign that the dairy industry has gained a more competitive structure. On the other hand, while improvements in price formation and price stability are observed, the quality standard and the existence of unfair competition conditions cannot be ignored. In this context, policies that encourage quality production in the dairy industry under conditions suitable for food codex should be developed and the supervision system should be strengthened.
\end{abstract}

\section{Araştırma Makalesi}

Makale Tarihçesi
Geliş Tarihi : 09.06 .2020

Kabul Tarihi : 25.08.2020

Anahtar Kelimeler

Süt Fiyatları

Fiyat Geçirgenliği

Asimetrik Hata Düzeltme Modeli

\footnotetext{
Atıf İçin: Ayyıldız M, Çiçek A, Kaplan K 2021. Türkiye'de Çiğ Süt ile Perakende Süt Fiyatları Arasındaki Asimetrik İlişki. KSÜ Tarım ve Doğa Derg 24 (3): 594-602. https://doi.org/10.18016/ksutarimdoga.vi.749975

To Cite : Ayyıldız M, Çiçek A, Kaplan K 2021. Asymmetrical Relationship Between Raw Milk and Retail Milk in Turkey. KSU J. Agric Nat 24 (3): 594-602. https://doi.org/10.18016/ksutarimdoga.vi.749975
}

\section{GíRiş}

Girdi fiyatlarının dinamik bir yapıda olmasından kaynaklanan istikrarsızlık ve bunun sektöre etkileri her zaman güncelliğini korumaktadır. $\mathrm{Bu}$ nedenle pazar zincirinde fiyat oluşumları ve birbirlerine etkisini araştıran çalışmalara sıklıkla yer verilmektedir (Aguiar ve Santana, 2002; Nakajima, 2011; Barahona ve ark., 2014). Özellikle son yıllarda 
fiyat geçirgenliğine yönelik yapılan çalışmalar ön plana çıkmaktadır (Acquaha ve Dadzie, 2010; Fernandez-Amador, 2010; Tekgüç, 2013; Bor ve ark., 2014; Fousekis ve ark., 2016; Çnar, 2017; Rezitis ve Tsionas, 2019). Fiyatlar arasındaki iletimin tespiti, fiyatlarda yaşanan istikrarsızlığın sektörün bütününe nasıl yansıdığının gösteren bir ölçümdür. Sektörde fiyat geçirgenliğinin yön ve hız bakımından belirlemesi ilgili sektörün pazarlama etkinliği ve verimliliğinin değerlendirilmesine katkı sağlamakla beraber tüketici ve üretici refahı hakkında bilgi sunmaktadır (Gomez ve Koerner, 2009). Özellikle arz zincirinin uzun ve halkaların geniş olduğu tarım sektörü ve onun alt sektörlerinde arz zinciri boyunca yaşanan aksaklıkların ortaya konulması ve buna yönelik çözüm arayışlarında fiyat iletiminin tespitine ilişkin analizler önemli bir araç olmaktadır (Popovics, 2008; Acosta ve Valdes, 2014; Bor ve ark., 2014; Çınar, 2017).

Süt fiyatlarındaki değişim, tüketicilerin bütçe paylaşımında önemli bir paya sahip iken diğer yandan üreticilerin çiğ süt arzında bulunmasında etken faktör olarak değerlendirilmektedir. Süt sanayicileri açısından ise çiğ süt fiyatlarındaki değişimler temel maliyet unsuru olarak değerlendirilmekte ve sektörel rekabette önemli bir paya sahip olmaktadır. Dünya'da ve Türkiye'de süt fiyatının oluşumu ve pazarlama kanalı fiyat aktarımına yönelik tartışmalar, genellikle perakende süt fiyatlarının üretici fiyatlarındaki azalışlardan ziyade artışlara daha hızlı tepki verdiği yönündedir (Serra ve Goodwin, 2003; Weldesenbet, 2013; Tekgüç, 2013; Bölük ve Karaman, 2015). Sadece fiyat karşılaştırmaları yaparak çiğ süt (üretici) ve perakende süt (tüketici) fiyatları arasındaki iletimi yorumlamak yetersizdir. Fakat genel olarak fiyat değişimlerinin seyrinin incelenmesi gerekir. Buna göre, Türkiye'de son 15 yılda çiğ süt ile perakende süt cari ve reel fiyatları incelendiğinde, 2005 yılında ortalama çiğ süt cari fiyatı 55 kuruş iken 2019 yılında 1.75 TL olduğu görülmektedir. Perakende süt cari fiyatı ise 2005 yllinda ortalama 1.60 TL iken 2019 yılında 4.37 TL'ye yükselmiştir. Buna göre son 15 yılda çiğ süt cari fiyatlarında $\% 218.18$ 'lik ve perakende süt fiyatlarında ise \%173.13'lük bir artış yaşanmıştır. Reel fiyatlara bakıldığında 15 yıllık süreçte perakende süt fiyatlarında \%21.21'lik, çiğ süt fiyatlarında ise \%15.21'lik bir azalış söz konusu olmuştur (Çizelge 1). Burada dikkat çeken husus perakende süt fiyatlarındaki artışlar çiğ süt fiyatındaki artışa göre daha az iken reel fiyatlardaki azalışlarda ise perakende süt fiyatlarının çiğ süt fiyatlarına oranla daha yüksek oranda olmasıdır.

Çizelge 1. Çiğ süt ve perakende bazında cari (TSF, USF) ve reel süt fiyatları (RTSF,RUSF)

Table 1. Current and real milk prices on raw (TSF, USF) milk and retail (RTSF,RUSF) basis

\begin{tabular}{|c|c|c|c|c|c|c|c|c|c|c|c|c|c|c|c|c|}
\hline & & 2005 & 2006 & 2007 & 2008 & 2009 & 2010 & 2011 & 2012 & 2013 & 2014 & 2015 & 2016 & 2017 & 2018 & 2019 \\
\hline \multirow{2}{*}{ TSF } & TL & 1.60 & 1.49 & 1.71 & 1.82 & 1.82 & 1.97 & 1.96 & 2.16 & 2.35 & 2.63 & 2.83 & 2.89 & 3.14 & 3.99 & 4.37 \\
\hline & $\%$ & & $-6,88$ & 14.77 & 6.43 & $\ldots$ & 8.24 & -0.51 & 10.20 & 8.80 & 11.91 & 7.60 & 2.12 & 8.65 & 27.07 & 9.52 \\
\hline \multirow{2}{*}{ RTSF } & $\mathrm{TL}$ & 1.32 & 1.16 & 1.22 & 1.18 & 1.11 & 1.11 & 1.03 & 1.04 & 1.06 & 1.09 & 1.08 & 1.03 & 1.01 & 1.10 & 1.04 \\
\hline & $\%$ & & -12.12 & 5.17 & -3.28 & -5.93 & $\ldots$ & -7.21 & 0.97 & 1.92 & 2.83 & -0.92 & -4.63 & -1.94 & 8.91 & -5.45 \\
\hline \multirow{2}{*}{ USF } & $\mathrm{TL}$ & 0.55 & 0.56 & 0.61 & 0.71 & 0.71 & 0.85 & 0.80 & 0.89 & 0.93 & 1.03 & 1.15 & 1.14 & 1.21 & 1.46 & 1.75 \\
\hline & $\%$ & & 1.82 & 8.93 & 16.39 & ...... & 19.72 & -5.88 & 11.25 & 4.49 & 10.75 & 11.65 & -0.87 & 6.14 & 20.56 & 19.86 \\
\hline \multirow{2}{*}{ RUSF } & $\mathrm{TL}$ & 0.46 & 0.43 & 0.44 & 0.45 & 0.45 & 0.49 & 0.42 & 0.43 & 0.44 & 0.44 & 0.47 & 0.44 & 0.41 & 0.39 & 0.39 \\
\hline & $\%$ & & -6.52 & 2.33 & 2.27 & $\ldots \ldots$ & 8.89 & -14.29 & 2.38 & 2,33 & $\ldots$ & 6.82 & -6.38 & -6.82 & -4.88 & $\ldots \ldots$ \\
\hline
\end{tabular}

${ }^{*} T L$ and\% represent Turkish lira and percentage change, respectively.

Sektörün sürdürülebilirliğinde fiyatların istikrarlı bir yapıda olması önemlidir. $\mathrm{Bu}$ bağlamda fiyat dalgalanmalarını dikkate alarak yapılan durum değerlendirmeleri daha sağlıklı olacaktır. 2005 Ocak- $^{-}$ 2019 Aralık dönemine ait aylık cari ve reel fiyat serilerine bakarak fiyat değişimlerini ve çĭ̆ süt ileperakende süt fiyatları arasındaki fark net bir şekilde görülmektedir (Şekil 1 ve 2).

Varyasyon katsayıları yardımıyla fiyat dalgalanmalarının yapısı incelendiğinde ise beklenildiği gibi enflasyonun etkisiyle cari fiyatlarda değişim oranı reel fiyatlara göre yüksektir. Yapılan hesaplamalarda varyasyon katsayısının perakende süt cari fiyatlarında \%34.84, çiğ süt cari fiyatlarında ise \%34.93 olduğu belirlenmiştir. 180 aylık gözlem dikkate alındığında bu katsayı değerlerinin yüksek olduğu söylenebilir. 2009-2019 dönemini baz alınarak hesaplanan varyasyon katsayısı oranlarının ise \%30’un altına düştüğü tespit edilmiştir. Bu durum da sektörde fiyat iyileştirmelerine yönelik uygulanan politikaların etkili olduğu söylenebilir.

Fiyat dalgalanmalarının düzeyinin reel fiyatlara bakarak değerlendirilmesi daha doğru olacaktır. Reel fiyatlar baz alınarak hesaplanan varyasyon katsayıları 180 aylık süreçte perakende süt fiyatlarında \%8.42, çiğ sütte ise $\% 7.35$ olarak belirlenmiştir. 2009 yllı sonrasındaki dönemde ise perakende süt fiyatlarındaki varyasyon katsayısında (\%4.76) önemli ölçüde azalma söz konusudur. Son yıllarda süt teşvik primi ve tavsiye fiyat uygulamaları gibi süt piyasasında yapılan düzenlemelerin fiyat istikrarını sağlamada etkili olduğu söylenebilir.

Fiyat oluşum ve yapıları olumlu sinyaller vermiş olsa da fiyat aktarımı konusunda net bir bilgi sağlamamaktadır. Gerek pazar etkinliğini gerek uygulanan politikaların işlevselliğini değerlendirebilmek için detaylı analizlere ihtiyaç 
duyulmaktadır. Öncelikle sektörde yaşanan gelişmelerin ve sorunların ele alınması gerekir. Bu fiyat geçirgenliğine ilişkin yapılan analizin gerekliliği ortaya koyma açısından da oldukça önemlidir.

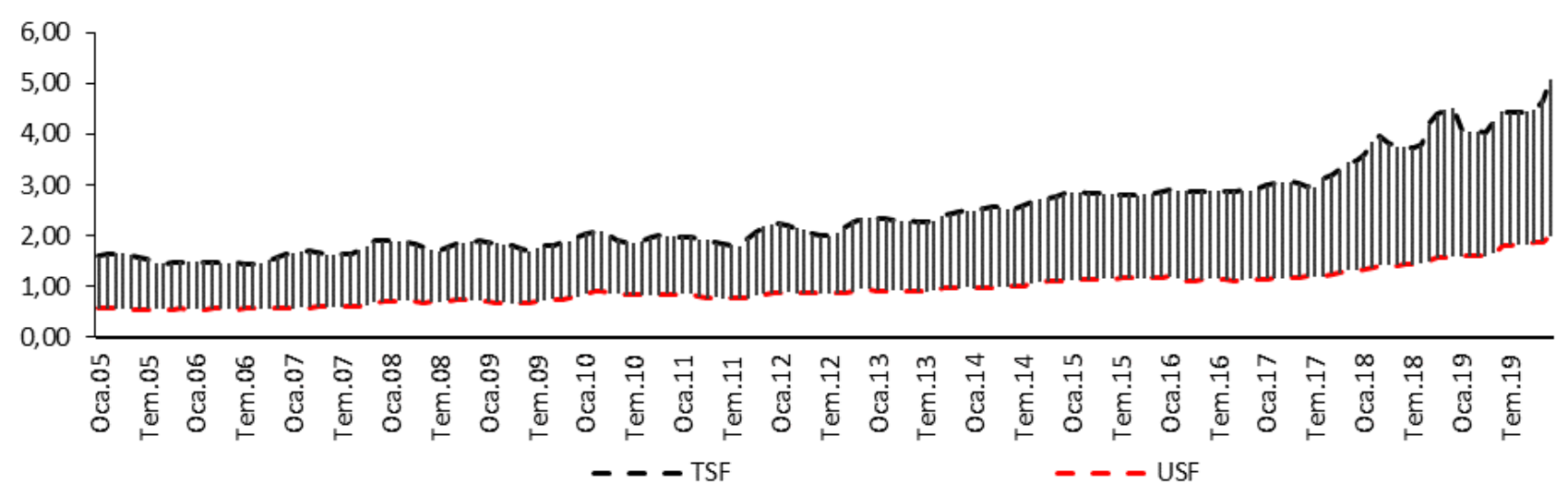

Şekil 1. Çiğ süt (USF) ve perakende süt (TSF) cari fiyatları

Figures 1. Current prices of raw milk (USF) and retail milk (TSF)

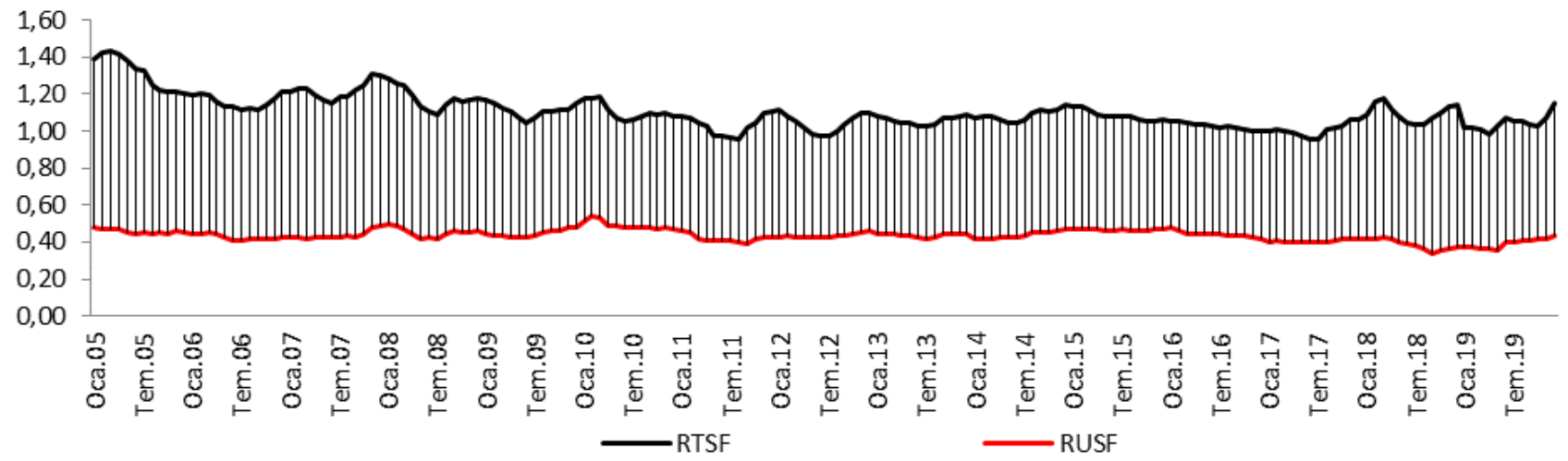

Şekil 2. Çiğ süt (RUSF) ve perakende süt (RTSF) reel fiyatları

Figures 2. Real prices of raw milk (RUSF) and retail milk (RTSF)

Türkiye'de son yıllarda uygulanan politikalar ile hayvansal ürün miktar ve değerinde artışlar yaşanmaktadır. 2018 yllında 225.33 milyar TL olan hayvansal üretim değerinde süt üretimi \%15.54'lük pay ile azımsanmayacak düzeyde gerçekleşmiştir. Üretimde inek sütü ön plana çıkmaktadır. Bunda yapisal ve kültürel etkiler söz konusu olduğu gibi son yıllarda büyükbaş hayvancılığa yönelik oluşturulan ve 20000000 geliştirilen politikaların etkisi yadsınamazdır. 2009 yılı itibariyle son on yıllık süreçte sağılan büyükbaş hayvan varlığında yaklaşık \%60’lık bir artış gözlenirken inek sütü üretim miktarındaki artış $\% 80$ oranında gerçekleşmiştir. Hayvan varlığındaki artışın yanı sıra süt veriminde de artış yaşanmıştır. Verim artışında kültür ve melez hayvan ırkındaki artışın etkili olduğu görülmektedir (Şekil 3).

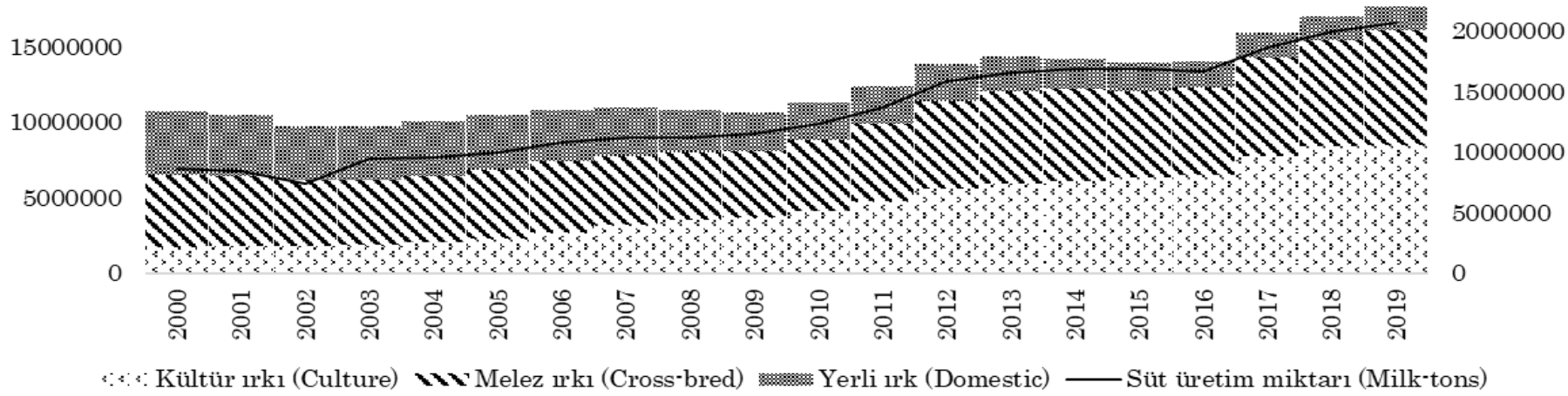

Şekil 3. Yıllar itibariyle hayvan varlığı ve süt üretim miktarı

Figures 3. Number of bovine animals by races and milk production by years 
Hayvan sayısı, süt verimi ve süt üretimindeki artışa rağmen sektöre ilişkin birçok yapısal problemin büyük ölçüde devam ettiğini söylemek yanlış olmayacaktır. Türkiye'de 2019 yllında 20.8 milyon ton inek sütü üretilmiş olmasına rağmen sadece $\% 46$ 'llk bir pay ile 9.56 milyon ton süt sanayiye aktarılmıştır (Anonim, 2020). Bu rakamlar sektörde kayıtdışılığın çok önemli bir sorun olduğunu göstermektedir. Süt sektöründe yaşanan bir diğer sorun süt üretim ve işleme tesislerinin ölçek yapısından kaynaklanmaktadır. Nitekim süt sığırcılığı işletmelerinin ölçek dağılımına bakıldığında 1 ile 5 hayvana sahip olan işletmelerin oranı \%50'nin üzerinde ve 1669 süt işletme tesisinin yaklaşık \%50.9'u 50000 tonun altında üretim yapan küçük ölçekli işletme niteliğindedir (Güneş, 2013; Anonim, 2018a). Temelde bu iki sorun üretilen sütlerin toplanmasını ve pazarlanmasını zorlaştırmakta, kaliteli süt erişimini engellemektedir. Dolayısıyla perakende süt üretim maliyetinin ve süt fiyatının artışına neden olmaktadır. Talep yönüyle bakıldığında ise kişi başına düşen içme sütü tüketimi yaklaşık 41.5 kg'dır ve bu rakam Avrupa Birliği ülkelerinde kişi başına içme sütü tüketim miktarı ile kıyaslandığında (64.9 kg/kişi) oldukça düşük kalmaktadır. Kayıtdışlıktan dolayı içme sütü tüketim miktarının gerçeği tam olarak yansıtmadığı bilinmektedir (Anonim, 2018b). Ayrıca tüketim miktarının istenilen seviyede olmaması süt arzındaki aksaklıklardan kaynaklanabilmektedir. Nitekim süt imalatçı firmaların tüketicinin talebini karşılayacak düzeyde yüksek kaliteli süte erişememesi süt sanayisi için önemli bir sorundur (Hekimoğlu ve Altındeğer, 2008; Günlü, 2011).

Süt üretim ve işleme maliyetleri ile talep yetersizliğinin yanı sıra perakende süt fiyatının belirlenmesinde çiğ süt fiyatı ve pazar yapısı oldukça önemlidir. Çĭ̆ süt perakende süt üretiminin hammaddesi olduğundan perakende süt fiyatının da temel belirleyicisidir. Bu bağlamda çiğ süt fiyatlarının nasıl ve neye göre belirlendiği oldukça önemlidir. Türkiye'de fiyat oluşumunda pazar yapısının büyük ölçüde etkili olabileceği varsayılmaktadır. Nitekim 100 000 tonun üzerinde üretim yapan işletme, sayı bakımından oldukça az olmasına rağmen pazarın yaklaşık \%40'ını oluşturmaktadır. Dolayısıyla gerek çiğ süt gerekse perakende fiyatlarının belirlenmesinde bu firmaların etkili olabileceği düşüncesi hakimdir (Hatırlı ve Özkan, 2004; Tekgüç, 2013). Diğer bir ifade ile oligopol piyasa yapısına sahip olan süt endüstrisinde çiğ süt ve perakende süt fiyatlarının belirlenmesinde rekabetçi anlayıştan uzaklaşllabileceği, üreticinin ve tüketicinin refah düzeyinde gerilemelerinin yaşanabileceği endişesi söz konusu olabilmektedir (Anonim, 2018).

Türkiye'de benzer çalışmalara rastlamak mümkündür (Tekgüç, 2013; Bölük ve Karaman, 2015). Fakat gıda fiyatlarının dinamik yapıda oluşu dikkate alındığında sektöre ilişkin kısa ve uzun vadeli politikaların geliştirilmesi açısından araştırma dönemleri büyük önem arz etmektedir. Bu bağlamda yakın döneme ilişkin literatürde bu kapsamda bir çalışma mevcut değildir. Diğer yandan sektördeki gelişmeler, mevcut sorunlar ve fiyat oluşumuna ilişkin endişeler dikkate alındığında, sektörün pazarlama etkinliği ve verimliliğinin değerlendirilmesi ile birlikte sektörün geliştirilmesine yönelik uygulanan politikalarm işlevselliğini ortaya koymada fiyat geçirgenliği tespitinin gerekli olduğu görülmektedir. Bu çalışma ile çiğ süt fiyatlarındaki değişimin perakende süt fiyatlarına ne yönde ve ne hızla yansıdığı belirlenmeye çalışılmıştır. Bu amaç doğrultusunda fiyat iletiminin tespitinde asitmetrik hata düzeltme modelinden yararlanılmıştır. $\mathrm{Bu}$ çalışmanın sektörün mevcut durumunu ortaya koymanın yanı sıra fiyat, üretim, pazarlama gibi politikaların oluşum ve gelişimine önemli ölçüde katkı sağlayacağı düşünülmektedir.

Çalışma giriş, materyal metod, bulgular ve tartışma ile sonuç ve öneriler olmak üzere dört (4) ana bölümden oluşmaktadır.

\section{MATERYAL ve METOD}

\section{Materyal}

Çalışmada üretici süt fiyatlarından (USF) tüketici süt fiyatlarına (TSF) doğru geçirgenlik ilişkini incelenmek amaciyla 2003 bazl fiyat endeksi dikkate alınarak Türkiye İstatik Kurumu veri portalında mevcut olan 2005 Ocak - 2019 Aralık dönemine ilişkin 180 aylık veri setinden yararlanılmıştır. Veri seti Türkiye İstatistik Kurumu'ndan temin edilmiştir. Çoğu zaman cari fiyatları baz alarak yapılan analizler hatalı ya da yanlış değerlendirmelere yol açabilmektedir. Bu nedenle daha rasyonel sonuçlar elde edebilmek için üretici süt fiyatları üretici fiyat indeksi (ÜFE=2003) ve tüketici süt fiyatları tüketici fiyat indeksi (TÜFE=2003) dikkate alınarak reel fiyat serilerine dönüştürülmüştür. Ayrıca varyansta kararlılık sağlamak ve aşırı boyutta olan gözlemlerin etkisini azaltabilmek amaciyla analiz aşamasında fiyat serileri logaritmik formda kullanılmıştır (Özer, 2011).

\section{Yöntem}

Süt sektöründe fiyat geçirgenliğinin incelendiği bu çalışmada öncelikle fiyat geçirgenliği tespitinde uygun model seçimi belirlenmeye çalışılmıştır. Bunun için ilk olarak serilerin durağanlık yapısı incelenmiştir. Her iki fiyat serisinin de aynı düzeyde durağan olduğu tespit edilmiş ve sonraki aşamada serilerin aynı düzeyde durağanlık koşulunu arayan eşbütünleşme testine geçilmiştir. Eşbütünleşme testi ile değişkenlerin uzun dönemde ilişkili olduğunun belirlenmesinin ardından fiyat geçirgenliğinin tespiti için asimetrik hata düzeltme modelinden 
yararlanılmıştır.

Serilerin durağanlık düzeyini ortaya koymada Genişletilmiş Dickey-Fuller (ADF) ve Phillips-Perron (PP) birim kök testlerinden faydalanılmıştır. ADF testi Dickey-Fuller (DF) testinin geliştirilmiş formudur. Buna göre $u_{t}$ hata terimlerinin bağımsız ve özdeş dağılmış olmasını varsayan DF testinin aksine ADF sınaması, bağımlı değişkenin gecikmeli değerlerini bağımsız değişken olarak modele dahil ederek hata terimlerinde var olabilecek otoregresif ilişkiyi hesaba katmaktadır. Burada gecikmeli değişkene ait uygun gecikme mertebesi belirlenirken Schwarz Information Criteria (SIC) yararlanılmıştır. PP birim kök testi ise hatalarda meydana gelen serisel korelasyon ve değişen varyans sorunu ile baş etme konusunda $\mathrm{ADF}$ ile farklılaşmaktadır. ADF denkleminde otokorelasyonu engellemek amacıyla gecikmeli değerlerin eklenmesi yerine PP sinamasında nonparametrik yöntemler yardımıyla DF denklemi tahmin edilerek $\mathrm{t}$ istatistikleri yeniden düzenlenmektedir. Her iki testte de temel hipotez birim kök var şeklindedir ve hipotezler $\mathrm{H} 0: \alpha=0$ ve $\mathrm{H} 1: \alpha<0$ olarak kurulur ve test istatistikleri MacKinnon kritik değerleri ile karşılaştırılır (MacKinnon, 1996). Ayrıca zaman serileri ile çalışıldığında mevcut değişkenlerin sabit ya da trend parametrelerinde herhangi bir şok etkisinden kaynaklanan yapısal değişikliler gözlenebilmektedir. Test aşamasında herhangi bir yapısal kırılma dikkate alınmamıştır.

Çiğ süt fiyatları ile perakende süt fiyatları arasındaki asimetrik ilişkinin tespitinde Von Cramon-Taubadel ve Loy'un (1999), Engel ve Granger (1987) hata düzeltme modelini geliştirdikleri asimetrik hata düzeltme modelinden yararlanılmıştır. Bu yaklaşım fiyat serilerinin eşbütünleşik olması durumunda tutarl sonuçlar vermektedir. Engel ve Granger hata düzeltme modeli iki aşamadan oluşmaktadır. İlk olarak, statik eşbütünleşme regresyonu tahmin edilir.

$T S F_{t}=\beta_{0}+\beta_{1} U S F_{t}+\varepsilon_{t}$

Eğer burada artıklar $\left(\varepsilon_{t}\right)$ seviyede durağanlık (I(0)) koşulunu sağlanıyorsa değişkenler arasında uzun dönemli ilişki olduğu söylenir. Ayrıca çalışmada eşbütünleşmenin varlığının ispatında Johansen (1998) eşbütünleşme testinden yararlanılmıştır. VAR modeli formunda olan bu yaklaşım, İz İstatistiği ve Maksimum Özdeğer $\left(\lambda_{\max }\right)$ istatistiğ değerlerinin istatistiki olarak anlamlı (Prob < 0.05) bulunması durumunda değişkenler arasında uzun dönemde bir ilişki yani eşbütünleşme olduğunu ileri sürmektedir. Değişkenler arasındaki kointegresyonun belirlenmesinin sonrasında denklem şu şekilde yazılabilir.

$T S F_{t}=\beta_{0}+\sum_{i=0}^{k} \beta_{1 i} \Delta U S F_{t-i}+\sum_{i=1}^{l} \beta_{2 i} \Delta T S F_{t-i}+$ $\beta_{3} E C T_{t-1}+\varepsilon_{t} \quad(2)$

Burada, Hata düzeltme terimi $\left(E C T_{t-1}\right)$ üretici fiyatları (USF) ve perakende fiyatları (TSF) arasındaki dengesizliklerin ne kadar sürede giderileceğini ifade etmektedir. $\beta_{1 i}$ ve $\beta_{2 i}$ ise kısa dönem dinamiklerini ölçmektedir.

Von Cramon-Taubadel (1998) Engel ve Granger'in hata düzeltme modelini geliştirerek asimetrik hata düzeltme modelini ortaya koymuşlardır. $\mathrm{Bu}$ modifikasyonda hata düzeltme terimini pozitif ve negatif şeklinde ayrılmaktadır. Daha sonra ise 1999 yılında hem hata düzeltme teriminin hem de dişsal fiyat değişkenlerinin ayrıştırılabileceği ayrıntılı bir tanımlama yapmışlardır (Von Cramon ve Taubadel, 1999). Bu çalışmada Asimetrik fiyat geçirgenliğinin tespiti için Von Cramon-Taubadel (1999) modeli denklem 3'teki gibi uyarlanmıştır.

$\Delta T S F_{t}=\beta_{0}+\sum_{i=0}^{k_{1}} \beta_{1 i}^{+} \Delta U S F_{t-i}^{+}+\sum_{i=0}^{k_{2}} \beta_{2 i}^{-} \Delta U S F_{t-i}^{-}+$ $\sum_{i=1}^{l} \beta_{3 i} \Delta T S F_{t-i}+\beta_{4}^{+} E C T_{t-1}^{+}+\beta_{4}^{-} E C T_{t-1}^{-}+\varepsilon_{t}$

Burada, $E C T_{t}^{+}=\left\{E C T_{t}>0\right.$ ise $E C T_{t}$, değil ise 0$\}$ ve $E C T_{t}^{-}=\left\{E C T_{t}<0\right.$ ise $E C T_{t}$, değil ise 0$\}$ şeklinde yazılır. Asimetrik hata düzeltme modelinde $\beta_{4}^{+}$ve $\beta_{4}^{-}$uzun dönem asimetriyi ölçen asimetrik uyum hızı katsayılarını, $\beta_{1 i}^{+}$ve $\beta_{2 i}^{-}$katsayıları $(i=1, \ldots ., k)$ ise kısa dönem asimetriyi ölçmektedir. Buna göre uzun dönemdeki simetri yokluk hipotezi $\beta_{4}^{+}=\beta_{4}^{-}$ile, kısa dönem için simetri yokluk hipotezi ise $\sum_{i=0}^{k_{1}} \beta_{1 i}^{+}=$ $\sum_{i=0}^{k_{2}} \beta_{2 i}^{-}$şeklinde kurulmakta ve fiyat geçirgenliğinin asimetrik ya da simetrik olması $\mathrm{F}$ istatistiği ile sinanmaktadır.

\section{BULGULAR ve TARTIŞMA}

\section{Birim Kök Testi Sonuçları}

Serilerin durağanlığının test edilmesi zaman serileri ile yapılan serilerin durağanlığını dikkate alan ekonometrik analizler için oldukça önemlidir. Çalışmada üretici ve tüketici süt fiyatları arasındaki asimetrik ilisskinin tespitinde kullanılan hata düzeltme modelinin uygulanabilmesi için ön koşul, kullanılan serilerin aynı düzeyde birim kök içermesidir. $\mathrm{Bu}$ amaçla Genişletilmiş Dickey-Fuller $(\mathrm{ADF})$ ve Phillips-Perron (PP) birim kök testlerinden faydalanılmıştır. Sabit ve hem sabit hem trend içeren birim kök sinamaları sonucunda perakende süt fiyatları (TSF) ve üretici süt fiyatları (USF) serilerinin birinci farkı alındığında durağan olduğu diğer bir ifade ile aynı düzeyde birim kök derecesine sahip oldukları tespit edilmiştir (Çizelge 2).

\section{Eşbütünleşme ile İlgili Sonuçlar}

Değişkenlerin aynı düzeyde durağanlık göstermesi seriler arasında eşbütünleşik bir ilişki olabileceği varsayımını kuvvetlendirmektedir. Değişkenler arasında eşbütünleşmenin varlığını ortaya koymak amaciyla Johansen (1988) eşbütünleşme testi uygulamasına gidilmiştir. Çizelge 3’te yer alan test hipotezleri incelendiğinde hiç koentegre vektör olmadığını gösteren $(\mathrm{r}=0)$ ve bir koentegre vektör 
olmadiğını gösteren $\quad(\mathrm{r}=1)$ yokluk hipotezleri reddedilmiştir. İz ve maksimum öz değer $\left(\lambda_{\max }\right)$ istatiklerinin birbiri ile uyumluluğu testin güvenilirliğini arttırmaktadır. Perakende süt fiyatları
(TSF) ve üretici süt fiyatları (USF) değişkenleri arasında koentegrasyon ilişkisi olduğu yani serilerin uzun dönemde birlikte hareket ettikleri belirlenmiştir.

Çizelge 2. ADF (Augmented Dickey-Fuller) ve PP (Phillips-Perron )birim kök testi sonuçları Table 2. ADF (Augmented Dickey-Fuller) and PP (Phillips-Perron ) unit root test results

\begin{tabular}{|c|c|c|c|c|}
\hline & \multicolumn{2}{|l|}{$\mathrm{ADF}$} & \multicolumn{2}{|l|}{$\mathrm{PP}$} \\
\hline & $\begin{array}{l}\mathrm{C} \\
\text { (Constant) }\end{array}$ & $\begin{array}{l}\mathrm{C} / \mathrm{T} \\
\text { (Constant and Trend) }\end{array}$ & $\begin{array}{l}\mathrm{C} \\
(\text { Constant })\end{array}$ & $\begin{array}{l}\mathrm{C} / \mathrm{T} \\
\text { (Constant andTrend) }\end{array}$ \\
\hline TSF & -3.603 & -3.106 & -2.828 & -2.531 \\
\hline USF & -3.351 & -3.558 & -2.931 & -3.045 \\
\hline$\Delta \mathrm{TSF}$ & -8.509 & -8.796 & -8.619 & -8.939 \\
\hline$\Delta \mathrm{USF}$ & -9.315 & -9.300 & -9.068 & -9.052 \\
\hline
\end{tabular}

${ }^{*} \mathrm{C}$ : sabit içeren birim kök testi, C/T: hem sabit hem de trend içeren birim kök testini ifade etmektedir.

${ }^{* *} \Delta$ birinci derece farkı alınmış seriyi göstermektedir. ( $\Delta$ shows the series with first degree difference.)

*** \%1 düzeyinde anlamlllığ ifade eden sabit, sabit ve trendi içeren MacKinnon(1996) kritik değerleri sırasıyla -3.467 ve 4.010 'drr. (The critical values of MacKinnon (1996) including constant, constant and trend that express significance at 1\% level are -3.467 and -4.010 , respectively.)

Cizelge 3. Johansen eşbütünleşme testi

Table 3. Johansen cointegration test

\begin{tabular}{|c|c|c|}
\hline & $\lambda_{\max }$ istatistiği ( $\lambda_{\max }$ statistic) & iz istatistiği (trace statistics) \\
\hline$r=0$ & $17.95579[14.26460]^{* * *}$ & $24.76016[15.49471]^{* * * k}$ \\
\hline$r=1$ & $6.804372[3.841466]^{* *}$ & $6.804372[3.841466]^{* *}$ \\
\hline
\end{tabular}

Fiyat iletiminin olası yönünü belirleyebilmek için Pairwise Granger nedensellik testinden yararlanılmıştır (Çizelge 4). Test sonuçlarına göre, üretici süt fiyatlarından (USF) perakende süt

Çizelge 4. Pairwise Granger nedensellik test sonuçları Table 4. Pairwise Granger causality test results

\begin{tabular}{|c|c|c|}
\hline & F istatistiği ( $F$-statistic) & Sonuç (Result) \\
\hline $\begin{array}{l}\mathrm{USF} \rightarrow \mathrm{TSF} \\
\mathrm{TSF} \rightarrow \mathrm{USF}\end{array}$ & $2.543^{* *}$ & $\mathrm{USF} \leftrightarrow \mathrm{TSF}$ \\
\hline
\end{tabular}

\section{Hata Düzeltme Modeli Sonuçları}

Üretici süt fiyatları ile perakende süt fiyatlarının koentegresyonu iki fiyat arasındaki simetrik ve asimetrik hata düzeltme modeli kullanımına olanak sağlar. Hata düzeltme modeli yardımıyla hem simetrik hem de asimetrik hata düzeltme terimleri analiz edilmiştir. Modelin gecikme uzunluğu Schwarz Information Criteria (SIC) göre 5 olarak belirlenmiştir. Çizelge 5'te simetrik ve asimetrik hata düzeltme modeli sonuçları verilmiştir. Simetri modelinde fiyatlardaki artış ve azalış bağımlı değişkende kesin olarak aynı etkiye sahiptir. Simetrik model sonucuna göre, hata düzeltme terimi beklenildiği gibi negatif işaretli ve $\% 5$ anlamlılık düzeyine sahiptir. Elde edilen hata terimi, tüketici süt fiyatlarının denge seviyesinde yaşanan sapmaların gelecek ayda \%6.8 oranında düzeltilebileceğini ve uzun dönemde ise sapmaların fiyatlarına (TSF) doğru \%5 anlamlllık düzeyinde ve perakende süt fiyatlarından (TSF) üretici süt fiyatlarına (USF) doğru \%1 anlamlılık düzeyinde çift yönlü nedensellik ilişkisi tespit edilmiştir. yaklaşık 15 ay gibi uzun bir süre içerisinde giderilebileceğini belirtmektedir.

Asimetrik hata düzeltme modelinde $\beta_{4}^{+}$ve $\beta_{4}^{-}$uzun dönem asimetriyi ölçen asimetrik uyum hızı katsayılarını, $\beta_{1 i}^{+}$ve $\beta_{2 i}^{-}$katsayıları $(i=1, \ldots \ldots, k)$ ise kısa dönem asimetriyi ölçmektedir. Tahmin edilen katsayılar pozitif hata terimlerinin $\left(E C T_{t-1}^{+}\right) \% 5$ seviyesinde önemli olduğunu gösterirken negatif hata terimlerinin $\left(E C T_{t-1}^{-}\right) \quad \% 5$ seviyesinde önemsiz olduğunu göstermektedir. Bu durum perakende süt fiyatlarının üretici süt fiyatlarına göre denge fiyatlarının üzerinde olduğu anlamına gelir. $\mathrm{Bu}$ nedenle perakende süt fiyatlarında gelecek aylarda düşüş olması beklenir.

Çizelge 6'da uzun ve kısa dönem fiyat geçirgenliğine ilişkin sonuçlar özetlenmiştir. Türkiye'de süt fiyatlarındaki asimetrik ilişkiyi inceleyen birkaç 
çalışma mevcuttur. Bu çalışmalarda çoğunlukla pozitif asimetrik ilişki belirlenmiştir. Örneğin; Tekgüç (2013), Bor ve ark. (2014), Bölük ve Karaman (2015) yapmış oldukları çalışmalarda bu çalışmada elde ettiğimiz negatif asimetrik ilişkinin aksi yönünde sonuca ulaşmışlardır. Diğer bir ifade ile perakende süt fiyatlarının çiğ süt fiyatlarındaki artışa daha hızlı cevap vererek artış eğiliminde olabileceğini ortaya koymuşlardır. Öte yandan çalışmada elde edilen bulgular Tekgüç'ün 2010 yılında yapmış olduğu Oligopoly and Price Transmission in Turkey's Fluid Milk Market isimli çalışmanın sonuçları ile benzerlik göstermektedir. Analiz dönemlerindeki ve tekniğindeki farklılıklar sonuçların farklı olmasında etkili olabileceği gibi özellikle dönemsel uygulanan fiyat politikalarının, sektördeki gelişmelerin ve rekabet artışının da fiyat geçirgenliğini önemli ölçüde etkileyebileceği göz ardı edilmemelidir. Nitekim 2010 yılı sonrasında hayvancılık politikalarına yönelik düzenlemeler yapılmış ve üretici ve sanayicilere yönelik destek ve teşviklerde artışlar söz konusu olmuştur. Bununla beraber uygulanan teşvik ve destek politikaları sektörün daha rekabetçi bir yapı kazanmasında etkili olabilmektedir.

Cizelge 5. Simetrik ve asimetrik hata düzeltme modeli

Table 5. Symmetric and asymmetric error correction model

Bağımlı değişken: $\triangle T S F$

Dependent variable: $\triangle T S F$

\begin{tabular}{|c|c|c|c|c|c|}
\hline \multicolumn{3}{|l|}{$\mathrm{ECM}$} & \multicolumn{3}{|c|}{ AECM } \\
\hline $\begin{array}{l}\text { Değişkenler } \\
\text { (Variables) }\end{array}$ & $\begin{array}{l}\text { Katsayı } \\
\text { (Coefficient) }\end{array}$ & $\begin{array}{l}\text { t-istatistiği } \\
(t-\text { statistic) }\end{array}$ & $\begin{array}{l}\text { Değişkenler } \\
\text { (Variables) }\end{array}$ & $\begin{array}{l}\text { Katsayı } \\
\text { (Coefficient) }\end{array}$ & $\begin{array}{l}\text { t-istatistiği } \\
(t \text {-statistic })\end{array}$ \\
\hline $\mathrm{c}$ & -0.002 & -1.242 & $\mathrm{c}$ & 0.005 & 1.261 \\
\hline$E C T_{t-1}$ & -0.068 & $-3.214^{* *}$ & $E C T_{t-1}^{+}$ & -0.128 & $-3.211^{* *}$ \\
\hline$\Delta U S F_{t}$ & 0.274 & $4.479^{*}$ & $E C T_{t-1}^{-}$ & 0.039 & 0.733 \\
\hline$\Delta U S F_{t-1}$ & -0.090 & -1.392 & $\Delta U S F_{t}^{+}$ & 0.393 & $3.726^{* * *}$ \\
\hline$\Delta U S F_{t-2}$ & -0.013 & -0.211 & $\Delta U S F_{t-1}^{+}$ & -0.108 & -0.990 \\
\hline$\Delta U S F_{t-3}$ & -0.057 & -0.881 & $\Delta U S F_{t-2}^{+}$ & -0.272 & $-2.494^{* *}$ \\
\hline$\Delta U S F_{t-4}$ & 0.203 & $3.127^{* *}$ & $\Delta U S F_{t-3}^{+}$ & -0.137 & -1.259 \\
\hline$\Delta U S F_{t-5}$ & 0.054 & 0.873 & $\Delta U S F_{t-4}^{+}$ & 0.116 & 1.083 \\
\hline$\Delta T S F_{t-1}$ & 0.203 & $2.479^{* *}$ & $\Delta U S F_{t-5}^{+}$ & 0.148 & 1.431 \\
\hline$\Delta T S F_{t-2}$ & -0.017 & -0.215 & $\Delta U S F_{t}^{-}$ & 0.169 & $1.668^{*}$ \\
\hline$\Delta T S F_{t-3}$ & 0.057 & 0.735 & $\Delta U S F_{t-1}^{-}$ & -0.051 & -0.487 \\
\hline$\Delta T S F_{t-4}$ & -0.318 & $-4.064^{* * *}$ & $\Delta U S F_{t-2}^{-}$ & 0.163 & 1.582 \\
\hline \multirow[t]{8}{*}{$\Delta T S F_{t-5}$} & -0.094 & -1.178 & $\Delta U S F_{t-3}^{-}$ & -0.068 & -0.655 \\
\hline & & & $\Delta U S F_{t-4}^{-}$ & 0.268 & $2.579^{* *}$ \\
\hline & & & $\Delta U S F_{t-5}^{-}$ & -0.070 & -0.711 \\
\hline & & & $\Delta T S F_{t-1}$ & 0.149 & $1.758^{*}$ \\
\hline & & & $\Delta T S F_{t-2}$ & 0.017 & 0.205 \\
\hline & & & $\Delta T S F_{t-3}$ & 0.142 & $1.753^{*}$ \\
\hline & & & $\Delta T S F_{t-4}$ & -0.332 & $-4.081^{* * *}$ \\
\hline & & & $\Delta T S F_{t-5}$ & -0.099 & -1.168 \\
\hline \multicolumn{2}{|l|}{$\mathrm{R}^{2}$} & 0.34 & \multicolumn{2}{|l|}{$\mathrm{R}^{2}$} & 0.39 \\
\hline \multicolumn{2}{|c|}{ DW } & 1.956 & \multicolumn{2}{|c|}{$\mathrm{DW}$} & 2.001 \\
\hline \multicolumn{2}{|c|}{ Breusch- godfrey LM test } & $1.364[0.259]$ & \multicolumn{2}{|c|}{ Breusch- godfrey LM test } & $2.084[0.128]$ \\
\hline \multicolumn{2}{|c|}{ Heterojenlik (ARCH) test } & $0.415[0.520]$ & \multicolumn{2}{|c|}{ Heterojenlik (ARCH) test } & $0.422[0.516]$ \\
\hline
\end{tabular}

Çizelge 6. Uzun ve kısa dönem fiyat geçirgenliğine ilişkin özet sonuçlar

Table 6. Summary results on long and short period price permeability

\begin{tabular}{lll}
\hline $\mathrm{Uzun}_{\text {dönem }}$ (Long-run) & \multicolumn{1}{c}{$\mathrm{K}_{1 \mathrm{sa}}$ dönem (Short-run) } \\
\hline $\mathrm{H}_{0}: \mathrm{ECT}^{+}=\mathrm{ECT}^{-}$ & $\mathrm{H}_{1}: \mathrm{ECT}^{+} \neq \mathrm{ECT}^{-}$ & $\mathrm{H}: \sum \Delta U S F^{+}=\sum \Delta U S F^{-} \quad \mathrm{H}_{1}: \sum \Delta U S F^{+} \neq \sum \Delta U S F^{-}$ \\
$\mathrm{F}(1.154)=4.079[0.0451]$ & & $\mathrm{F}(1.154)=0.717884[0.3982]$ \\
Negatif asimetrik ilişki (Negative asymmetric) & Simetrik (Symmetric) \\
\hline
\end{tabular}

\section{SONUÇ ve ÖNERILLR}

Süt sektöründe yapısal sorunlar devam etmekle birlikte son yıllarda hayvancılığa yönelik politikaların iyileştirilmesi, sektörün gelişiminde önemli ölçüde etkili olmuştur. Bu gelişimin fiyat oluşumuna ve fiyatların istikrarlı bir yapıya kavuşmasına katkı sağladığı söylenebilir. Üretici süt fiyatlarının Ulusal Süt Konseyi'nin tavsiye fiyat uygulaması ile belirlenmesi ve üreticilere süt teşvik primi ödenmesi, örgütlenme düzeyindeki gelişmeler ve rekabetin artmasının fiyat oluşumu ve istikrarında etkili olduğu 
ifade edilebilir. Ayrıca çiğ süt fiyatlarının belirlenmesine yönelik getirilen düzenlemeler ile süt sanayicilerinin üreticiler üzerindeki fiyat baskısı azalmış ve çiğ süt fiyatlarını düşük bulan üreticilerde kısmen refah artışı sağlanmıştır. Perakende süt fiyatlarına bakıldığında ise, yıllar itibariyle fiyatlardaki artış oranları azalmakta ve çiğ süt fiyatlarının artış oranlarının gerisinde bir artış göstermektedir.

Perakende ve çiğ süt fiyatları arasındaki ilişkiyi somut bir şekilde ortaya koymak amacıyla 180 aylık dönemde süt fiyatları arasındaki geçirgenliğin incelendiği bu çalışmanın bulguları uzun dönemde negatif fiyat asimetrisi olduğu yönündedir. Buna göre, uzun dönemde perakende süt fiyatlarını, çĭ̆ süt fiyatlarındaki azalmaya, artışa oranla daha hızlı tepki verdiği görülmektedir. Diğer bir ifadeyle perakendeciler, çiğ süt fiyatlarındaki azalmaya fiyat indirimi ile karşılık vermektedir. $\mathrm{Bu}$ durum süt sanayisinin daha rekabetçi bir yapı kazandığına önemli bir işaret olarak kabul edilebilir. Son yıllarda içme sütünde ürün çeşitliliğinin yanı sıra fiyat eğilimini etkileyecek düzeyde marka çeşitliliğindeki artış dikkat çekmektedir. Firma sayısındaki bu artış, rekabeti arttırmakta ve fiyatların serbest piyasa koşularında oluşmasında etken faktör olmaktadır. Ayrıca teknolojinin gelişimi doğrultusunda içme sütünün raf ömrünün uzaması negatif fiyat geçirgenliğini açıklayan bir diğer unsur olabilmektedir.

Sonuç olarak fiyatlar yönüyle bakıldığında üretici ve tüketici refahında bir artış olduğu söylenebilir. Bununla birlikte süt teşvik primi uygulaması ile süt kalitesinde bir homojenlik sağlanmadığ ziyade üretimin ön planda tutulduğu dikkat çekmektedir. Firma sayısındaki artış fiyatlar üzerinde olumlu etkide bulunurken kalite standardı ile haksız rekabet koşullarının giderilmesi gerekmektedir. $\mathrm{Bu}$ bağlamda, süt sanayiinde gida kodeksine uygun şartlarda kaliteli üretimi de teşvik eden politikalar geliştirilmeli ve buna yönelik denetim sistemi güçlendirilmelidir.

\section{Araştırmacıların Katkı Oranı Beyan Özeti}

Yazarlar makaleye eşit oranda katkı sağlamış olduklarını beyan ederler.

\section{Çıkar Çatışması Beyanı}

Makale yazarları aralarında herhangi bir çıkar çatışması olmadığını beyan ederler.

\section{KAYNAKLAR}

Acosta A, Valdés, A 2014. Vertical Price Transmission of Milk Prices: Are Small Dairy Producers Efficiently Integrated into Markets? Agribusiness 30(1): 56-63.
Acquah H, Dadzie, SKN 2010. An Application of the von Cramon-Taubadel and Loy Error Correction Models in Analyzing Asymetric Adjustment Between Retail and Wholesale Maize Prices in Ghana. Journal of Development and Agricultural Economics, 2(4): 100-106.

Aguiar DRD, Santana JA 2002. Asymmetry in Farm to Retail Price Transmission: Evidence from Brazil. Journal of Agribusiness 18(1): 37-48.

Amador OF, Baumgartner J, Cuaresma JC 2010 Milking the Prices: The Role of Asymmetries in the Price Transmission Mechanism for Milk Products in Austria. Working Papers 378. Working Paper of WIFO.

Anonim 2020. Hayvan Varlığı ve Süt Üretim Miktarı, 2000-2019. www.tuik.gov.tr (Alınma Tarihi: 21.04.2020).

Anonim 2018a. Süt sektör politika belgesi. https://www.tarimorman.gov.tr/TAGEM/ Belgeler/ yayin/S\%C3\%BCt\%20Sekt\%C3\%B6r\%20Politika\% 20Belgesi\%202018-2022.pdf (Alınma Tarihi: 21.04.2020).

Anonim 2018b. Süt Sektörü Raporu. http://zmo.org.tr/ genel/bizden_detay.php? $\quad$ kod $=\quad 31590 \&$ tipi $=$ 38\&sube $=0$ (Alınma Tarihi 21.04.2020).

Bölük G, Karaman S 2015. Süt Arz Zincirinde Aksak Rekabet Koşullarının Asimetrik Hata Düzeltme Modeli ile Analizi. Rekabet Dergisi 16(1): 3-40.

Bor Ö, Ismıhan M, Bayaner A 2014. Asymmetry in farm-retail price transmission in the Turkish fluid market. New Medit, 2: 2-8.

Çınar G 2017. Çiftlik Sütü Fiyatlarından Yoğurt ve Peynir Pazarına Asimetrik İletim. Tarım Ekonomisi Dergisi 23(1): 93-99.

Dickey DA, Fuller WA 1981. Likelihood Ratio Statistics for Autoregressive Time Series with a Unit Root. Econometrica, 49(4): 1057-1072.

Engel R, Granger C 1987. Co-integration and Error Correction: Representation, Estimation and Testing. Econometrica, 55(2): 251-276.

Fousekis P, Katrakilidis C, Trachanas E 2016. Vercital Price Transmission in the US Beef Sector: Evidence from The Nonlinear ARDL Model. Journal of Economic Modelling, 52(B): 499-506.

G MI, Koerner L 2009. Do Retail Coffee Prices Increase Faster than They Fall? Asymmetric Price Transmission in France, Germany and The United States. Working Paper of Department of Applied Economics and Management Cornell University, Ithaca, New York.

Günlü A 2011. Çiğ Süt Pazarlamasında Süt Sanayi İşletmelerinde Firma Yoğunlaşma Oranlarının Araştırılması: Burdur İli Örneği. Kafkas Üniversitesi Veterinerlik Fakültesi Dergisi, 17(1): 101-106.

Hatırlı SA, Özkan B 2004. Türkiye Süt ve Süt Ürünleri Sektöründe Oligopson Gücünün Araştırılması. Türkiye VI Tarım Ekonomisi Kongresi, 16-18 Eylül 
2004, Tokat.

Hekimoğlu B, Altındeğer M 2008. Ülkemizde ve Samsun İlinde; Süt Hayvancılığı ve Süt Sektöründeki Mevcut Durum, Sorunlar ve Öneriler. Samsun Tarım İl Müdürlüğü Raporu.

Johansen S 1988. Statistical Analysis of Countegration Vectors. Journal of Economic Dynamics and Control, 12(2-3): 231-254.

MacKinnon JG 1996. Numerical Distribution Functions for Unit Root and Cointegration Tests. Journal of Applied Econometrics 11: 601-618.

Nakajima J 2011. Time-Varying Parameter VAR Model with Stochastic Volatility: An Overwiew of Methodology and Empirical Applications. Monetary and Economic Studies 29: 107-142.

Özer OO 2011. Koyun Eti Fiyatının Asimetrik Fiyat Geçirgenliği ile Analizi: Türkiye Örneği. Tarım Ekonomisi Dergisi 17(2): 55-63.

Perron P 1997. Further Evidence on Breaking Trend Functions in Macroeconomic Variables. Journal of Econometrics 80(2): 355-385.
Popovics PA 2008. Analysis of Economic Issues Relating to The Dairy Sector, with Emphasis on Price Transmission. Applied Studies in Agribusiness and Commerce, 2(1-2): 61-70.

Rezitis AN, Tsionas M 2019. Modelling Asymmetric Price Transmission in the European Food Market. Journal of Economic Modelling, 76: 216-230.

Serra T, Goodwin BK 2003. Price Transmission and Asymmetric Adjustment in The Spanish Dairy Sector. Applied Economics, 35(18): 1889-1899.

Tekgüç H 2013. Oligopoly and Price Transmission in Turkey's Fluid Milk Market. Journal of Agribusiness, 29(3): 293-305.

Von Cramon-Taubadel S, Loy JP 1999. The Identification of Asymmetric Price Transmission Processes with Integrated Time Series. Jahrbücher für Nationalökonomie und Statistik 218(1-2): 85106.

Weldesenbet T 2013. Asymmetric price transmission in the Slovak liquid milk market. Agricultural Economics 59: 512-524. 